Rev. Biol. Trop. 46(4): 1109-1115, 1998

www.ucr.ac.cr www.ots.ac.cr www.ots.duke.edu

\title{
Effect of saline solutions and salt stress on seed germination of some tropical forest tree species
}

\author{
D. A. Agboola
}

Department of Biological Sciences, University of Agriculture, Abeokuta, Ogun State, Nigeria. Fax 23439243045.

Received 4-III-1997. Corrected 21-IX-1998. Accepted 5-X-1998.

\begin{abstract}
The effect of several saline solutions (as given by six salts) and salt stress (as given by $0.1-2 \mathrm{~m}$ sodium chloride solutions) on the germination of seeds of six selected tropical forest tree species was investigated. Saline solutions $(0.2 \mathrm{~m})$ of the six salts used had highly significant effects on seed germination in most of the tree species. Sodium suphate (Na2So4) permitted germination in the seeds of Ceiba pentandra and Tectona grandis presoaked in its $0.2 \mathrm{~m}$ solution for 36 and $48 \mathrm{~h}$ respectively. The Zinc sulphate ( $\mathrm{ZnSO} 4$ ) solution enhanced the germination of seeds of Terminalia ivorensis and Terminalia superba. Solution of Potassium permanganate favoured the germination of seeds of $T$. grandis, $T$. ivorensis and $T$. superba. In general, increase in molar concentration of $\mathrm{NaCl}$ adversely affected the germination rate of seeds. Sees of the two Terminalia species could withstand $\mathrm{NaCl}$ salt stress. Seed s of $T$. grandis have high ability to withstand salt stress comparatively.
\end{abstract}

Key words: Saline solutions, salt stress, forest trees, seed germination.

In tropical soils, underground water which forms the major source of water supply for the forest trees is subjected to frequent salinisation. When the evaporative power of air is high and when water is being pumped out from the sal ine water table, the surface inch of the soil frequently becomes more saline than the subsurface (El - Sharkawi and Springuel 1979). In the tropics also, saline soils are typified by lagoons and mangrove swamps. In some wet rainforest near the sea, toxic concentrations do not often occur in such soils because the soluble constituents are carried away in drainage water to the water table below the root range (Ewusie 1980).

A soil is saline when its total soluble salt content is excessive. That is when there are enough salts to affect plant growth adversely. Growth of sensitive plants becomes impaired when the salt content of the soil exceeds about $0.1 \%$. Various salts of which Sodium, Calcium and Magnessium are most common, contribute to Salinity. High levels of fertilization also contribute to salt accumulation and can be significant in agricultural situations (Treshow 1970). Soil salinity affects soil water potentials, $\mathrm{pH}$, 
microbial acitvity. High concentrations of salts are expected in arid Land ecosystems, but salinity is also important in some expected situations such as heavily forested river courses in these saline regions of the tropics (Pearcy 1994).

Therefore the seed is generally in a more saline environment than the established plants whose roots can use less saline portion of the soil profile. The factor of high evaporation, transpiration and concentration of salts on soil surface coupled with greater inherent sensitivity to salt are responsible for most emergence failures on these saline soils of the coastal as well as the arid and semi arid regions of the tropics (Ayers 1952, Ewusie 1980).

The tropical tree species investigated include Ceiba pentandria, Terminalia ivorensis, Terminalia superba, Tectona grandis, Gmelina arborea and Leucaena leucocephala. The first three are indigenous timber producing trees of the rainforest belft of Nigeria, while the latter three are exotic species introduced from some other tropical zones (especially South East Asia) and thrive well in the Savannah and rainforest regions of Nigeria. Leucaena has been of immense importance in various agroforestry practices in Nigeria for Nitrogen fixation and therefore adding nutrients to the soil and crops in alley cropping (Kang 1987).

Most of the tree species especially $T$. superba and T. ivorensis face the problem of extinction due to over exploitation (Onochie 1991). The aim of this investigation is to study the effect of salt strees and saline conditions on the germination of seeds of six of the tropical tree species commonly in use in Nigeria and other tropical zones of the world. The information from this study will hopefully enhance various nursery practices with a view to having successful germination and seedling procurement.

\section{MATERIALS AND METHODS}

The effect of six several saline solutions $(0.2 \mathrm{~m})$ mostly encountered in tropical soils, was first studied assuming that tropical soil solutions contain mixtures of most of these salts (Shabassy et al. 1970, Treshow 1970). This was followed by the study of the effect of different levels as given by $0.1-2 \mathrm{~m}$ sodium chloride $(\mathrm{NaCl})$ solutions on the germination of seeds. The choice of $\mathrm{NaCl}$ is based on its common occurence and stability in tropical soils, where these tree species grow (Ungar 1962, Nelson 1965).

Dry pretreated (dormancy - free) seeds in each case were surfaced sterilized with $0.1 \%$ mercuric chloride solution for 10 seconds and then rinsed several times with distilled water. Seeds were divided into lots and pre-soaked in $0.2 \mathrm{M}$ solutions of Sodium chloride $(\mathrm{NaCl})$, Potassium permanganate $\left(\mathrm{KMNO}_{4}\right)$, Ammonium Chloride $\left(\mathrm{NH}_{4} \mathrm{Cl}\right)$, Sodium Sulphate $\left(\mathrm{Na}_{2} \mathrm{SO}_{4}\right)$, Zinc Sulphate $\left(\mathrm{ZnSO}_{4}\right)$ and Calcium Carbonate $\left(\mathrm{CaCO}_{3}\right)$, for period of $0,24,36$ and 48 hours. The effect of the solutions gave osmotic pressures of between 4 to $15 \times 10^{5}$ pascals (Ungar 1962, Elsharkawi et al. 1979). Water served as the control.

The seeds under each treatment were then prepared for germination, for which 25 seeds were plated in $9 \mathrm{~cm}$ (except $T$. grandis in $20 \mathrm{~cm}$ ) sterile glass Petri dishes lined with sterile filter papers and moistened with $20 \mathrm{ml}$ sterile distilled water. Five replicates from each treatment were placed in germination cabinets running at constant temperature of $30 \pm^{\circ} \mathrm{C}$ and an alternating day/night regime of $30 / 27^{\circ} \mathrm{C}$. Twelve hours periods of lights were used per day and seeds were watered when necessary.

In another experiment, different lots of the pretreated seeds of the six species were plated for germination as earlier described. However, instead of distilled water, seeds in the petri dishes were moistened with $20 \mathrm{ml}$ of Nacl solution. Solutions ( 0.1 to $2 \mathrm{M})$ giving a total of 12 treatments, with water serving as the control. The solutions of $\mathrm{NaCl}$ were prepared according to the methods described by Devlin (1969) (Table 1). The experimentation was randomized block design. The mean values of 5 replicates were calculated and data subjected to analysis of variance (ANOVA). Moreover the significant differences between treatment 
TABLE 1

Molar Concentrations of Sodium chloride solutions used and their corresponding osmotic pressures

$\begin{array}{lcc}\begin{array}{l}\text { Molar Concentration } \\ \text { of } \mathrm{NaCl}(\mathrm{M})\end{array} & \begin{array}{c}\text { Osmotic } \\ \text { Pressure } \\ \text { (x 105 pascals) }\end{array} & \begin{array}{c}\text { Osmotic } \\ \text { Pressures (ATM) }\end{array}\end{array}$

$\begin{array}{ccc}0.0\left(\mathrm{H}_{2} \mathrm{O}\right) & & \\ 0.0 & 0.0 & \\ 0.1 & 3.84 & 3.8 \\ 0.2 & 7.68 & 7.6 \\ 0.3 & 11.51 & 11.4 \\ 0.4 & 15.35 & 15.2 \\ 0.5 & 15.4 & 19.2 \\ 0.6 & 22.6 & 22.4 \\ 0.7 & 26.8 & 26.6 \\ 0.8 & 30.7 & 30.4 \\ 0.9 & 34.5 & 34.2 \\ 1.0 & 38.4 & 38.0 \\ 2.0 & 72.7 & 72.0\end{array}$

means and control were compared by the least significant differences test (LSDT) $(\mathrm{P}=0.05)$.

\section{RESULTS}

The results of the effect of six different salt solutions on the total percentage of germinated seeds of six tropical tree species are as shown on tables 2 and 3. It was observed that various solutions had a highly significant effect on the germination of seeds in most of the tree species.

Ceiba pentandra showed that $0.2 \mathrm{M}$ $\mathrm{Na}_{2} \mathrm{SO}_{4}$ solution decreased seed germination. Thus, over 43 - 52\% germination was recorded in seeds of $C$. pentandra presoaked for 36 and $48 \mathrm{~h}$ respectively (Tables 2 and 3 ) Germination was as low as $3-10 \%$ in C. pentandra and $T$. superbs in other salt solutions. None of the $0.2 \mathrm{M}$ solutions of $\mathrm{CaCO}_{3}$ and $\mathrm{ZnSO}_{4}$ permitted germination of seeds in most of the tree species. The exceptions were $T$. ivorensis and $T$. superba where seeds presoaked in $0.2 \mathrm{M}$ solutions of $\mathrm{CaCO}_{3}$ for $24 \mathrm{~h}$. gave 46 and $55 \%$ of total germination. The solution of $\mathrm{KMNO}_{4}$ was observed to enhance the germination of seeds of $T$. grandis, $T$. ivorensis and T. superba (Table 3). About 70 $100 \%$ total germination was observed in their seeds presoaked in $0.2 \mathrm{M}$ of this salt solution for 36 - 48h (Tables $2 \& 3$ ).

The total percentage of germinated seeds in all the tree species investigated was adversely affected by increase in Molar concentration of $\mathrm{NaCl}$ solution when compared to water. This effect is seen in the form of poor or delayed germination (Figs. 1-6). The results showed that $T$. superba, T. ivorensis and $T$. grandis seeds could withstand some salt stress of $\mathrm{NaCl}$ though the total percentage germination was decreased in the stronger solution $(0.9-1.0 \mathrm{M})$ (figs. $3 \& 4)$. There was no germination of seeds under $2.0 \mathrm{M} \mathrm{NaCl}$ solution except those of $L$. leucocephala and $T$. grandis where $18-36 \%$ total germination was recorded (figs. $1 \& 6$ ). The results in general showed that seeds of $T$. grandis have high ability to withstand salt stress when compared with others (figs. $1 \& 6$ ).

\section{DISCUSSION}

Salt solutions with concentration as low as $0.2 \mathrm{M}$ did not permit germination in seeds of the six tree species with the exception of $\mathrm{NaSO}_{4}, \mathrm{KMNO}_{4}$ and $\mathrm{NaCL}$ (Tables $2 \& 3$ ). Increase in concentration of $\mathrm{NaCl}$ up to $1 \mathrm{M}$ and $2 \mathrm{M}$ affected germination adversely as shown in the form of delayed germination and very low percentage germination. However, seeds of $T$. grandis and Terminalia species could withstand stress solutions of relatively high molar concentration of $\mathrm{NaCl}$ (figs. 3, 4 \& 6). Some of the results obtained in this study are similar to those of some other workers who showed that in general, increased salinity results in decrease in germinability and delayed rate of germination (Palmer et al. 1969, Alekseeva 1973, Elsharkawi and Springuel 1979). Sonaike and Okusanya (1987) showed that salinity caused a loss in germination of Lufa aegyptica seeds at a concentration of $10 \%$ sea water. They found that germination decreased as salinity increased. This is also true 
TABLE 2

Effect of different types of salt solutions on the germination of seeds of some tropical tree species. Data are means of five replicates

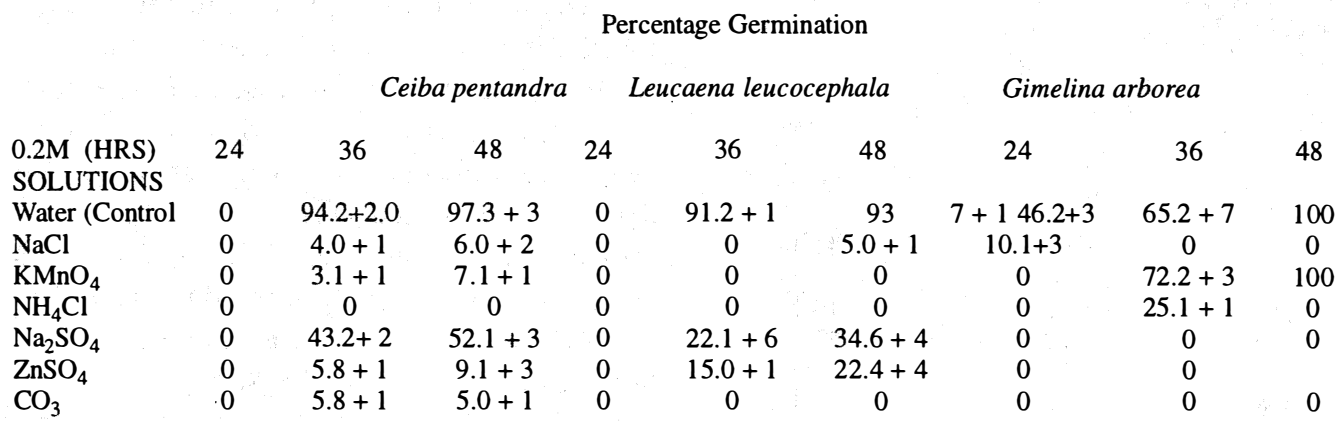

\section{TABLE 3}

Effect of different types of salt solutions on the germination of seeds of some tropical tree species. Data are means of five replicates

$\begin{array}{lccccccccc}\text { Solutions (HRS) } & 24 & 36 & 48 & 24 & 36 & 48 & 24 & 36 & 48 \\ & & & & & & & & & \\ \text { Water (Control) } & 0 & 94.2+2.0 & 97.3+3 & 0 & 91.2+1 & 93.7+1 & 46.2+3 & 65.2+7 & 100 \\ \mathrm{NaC}_{1} & 0 & 4.0+1 & 6.0+2 & 0 & 0 & 5.0+1 & 10.1+3 & 0 & 0 \\ \mathrm{KMnO}_{4} & & & 0 & 3.1+1 & 7.1+1 & 0 & 0 & 0 & 0 \\ 72 & 2+3 & 100 & & & & & & & \\ \mathrm{NH}_{4} \mathrm{Cl} & 0 & 0 & 0 & 0 & 0 & 0 & 0 & 25.1+1 & 0 \\ \mathrm{Na}_{2} \mathrm{SO}_{4} & 0 & 43.2+2 & 52 & 1+3 & 0 & 22.1+6 & 34.6+4 & 0 & 0 \\ \mathrm{ZnSO}_{4} & 0 & 5.8+1 & 9.1+3 & 0 & 15.0+1 & 22.4+4 & 0 & 0 & 0 \\ \mathrm{CaCO}_{3} & 0 & 5.8+1 & 5.0+1 & 0 & 0 & 0 & 0 & 0 & 0\end{array}$

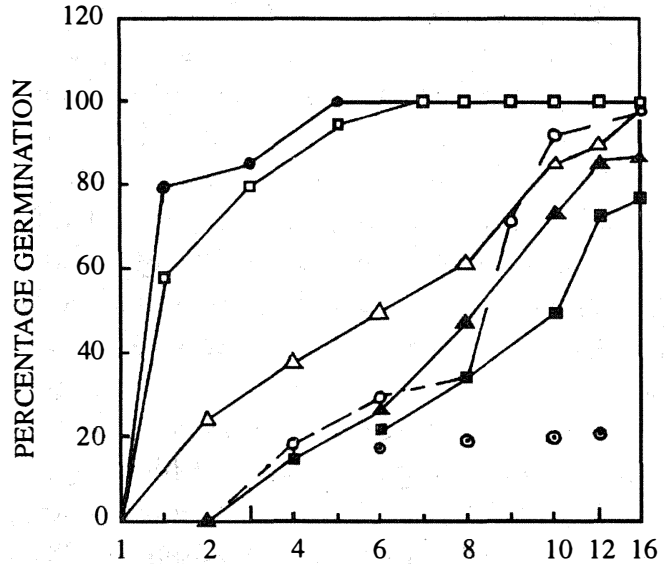

Fig. 1. Effect of $\mathrm{NaCl}$ level on germination of Leucaena leucocephala seeds

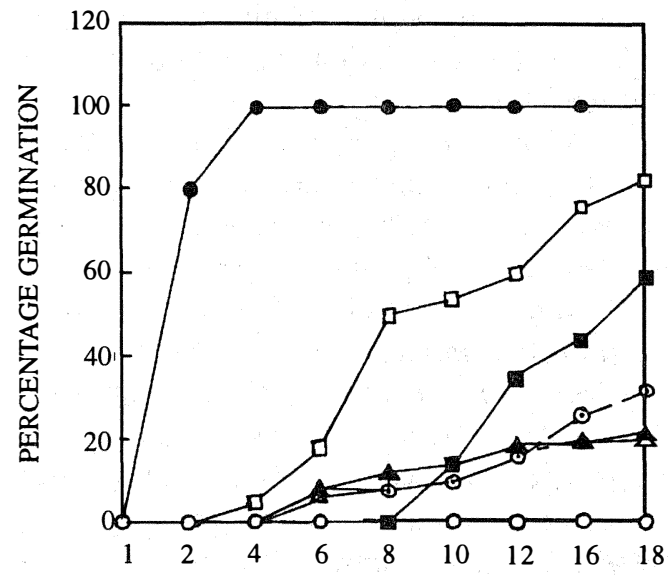

Fig. 2. Effect of $\mathrm{NaCl}$ stress on germination of Ceiba pentandra seeds. 


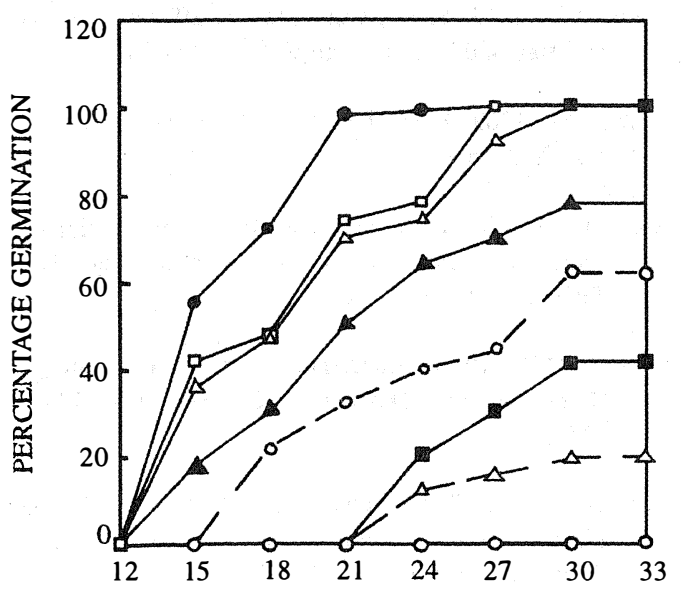

Fig. 3. Effect of $\mathrm{NaCl}$ stress on germination of Terminalia superba seeds.

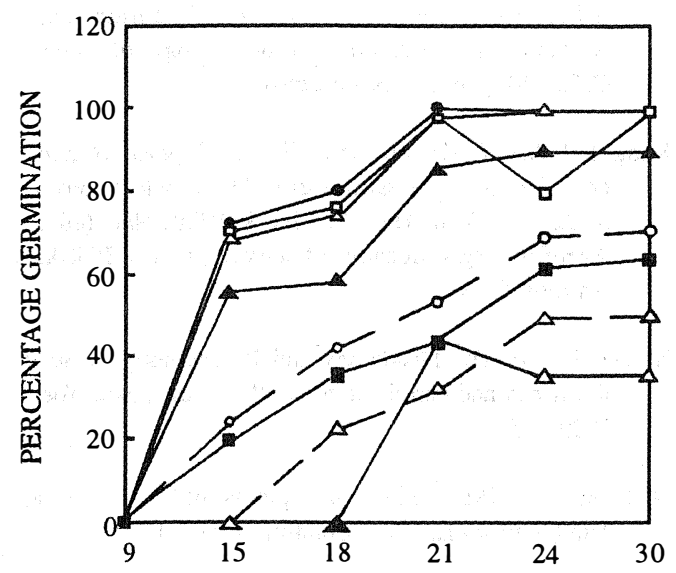

Fig. 5. Effect of level of $\mathrm{NaCl}$ on germination of Tectona grandis seeds.

of Eucalyptus degulpta and E. camaldulensis (Vandermoezel and Bell 1987).

The effect of salts in solution on germination of seeds is generally complex. Discrepancies are numerous as limits between predominant osmotic effect and the toxic effect of one and same salts are not

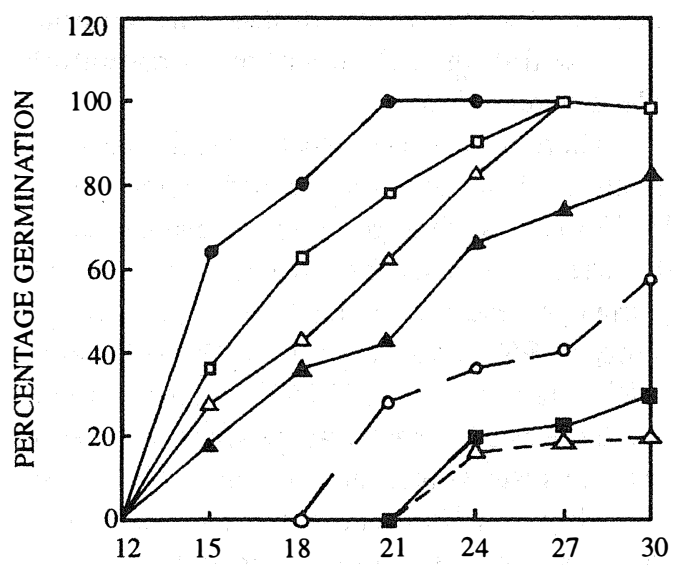

Fig. 4. Effect of levels of $\mathrm{NaCl}$ on germination of Terminalia ivorensis seeds.

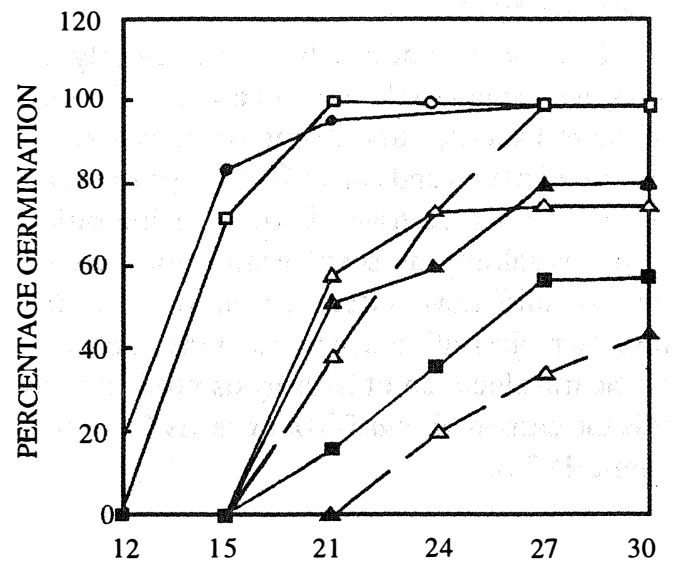

Fig. 6. Effect of $\mathrm{NaCl}$ stress on germination of Gmelina arborea seeds.

defined. Solution of $\mathrm{Na}_{2} \mathrm{SO}_{4}$ decreased germination especially in seeds of $C$. pentandra and L. leucocephala (Table 2). The promotion of germination by some salts in solution has been demonstrated many times (Devlin 1969). The most popular and widely used is Potassium nitrate. This enhancement effect 